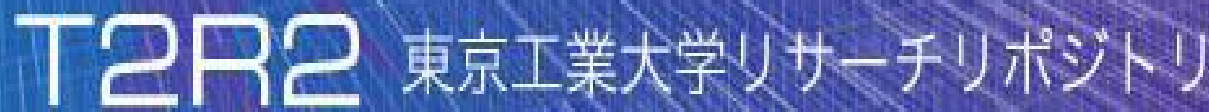

\section{Tokyo Tech Research Repository}

\section{論文 /著書情報 \\ Article /Book Information}

\begin{tabular}{|l|l|}
\hline Title & Investigation of Repetitive Bending Durability of Synthetic Fiber Ropes \\
\hline Cuthors & Atsushi Horigome, Gen Endo \\
\hline Pub. date & IEEE Robotics and Automatoin Letters, Vol. 3, No. 3, pp. 1779-1786 \\
Copyright & $\begin{array}{l}\text { 2018, } 1 \\
\text { (c) 2018 IEEE. Personal use of this material is permitted. Permission } \\
\text { from IEEE must be obtained for all other uses, in any current or future } \\
\text { media, including reprinting/republishing this material for advertising or } \\
\text { promotional purposes, creating new collective works, for resale or } \\
\text { redistribution to servers or lists, or reuse of any copyrighted component } \\
\text { of this work in other works. }\end{array}$ \\
\hline Dol & $\begin{array}{l}\text { This file is author (final) version. } \\
\text { note }\end{array}$ \\
\hline
\end{tabular}




\title{
Investigation of Repetitive Bending Durability of Synthetic Fiber Ropes
}

\author{
Atsushi Horigome ${ }^{1}$ and Gen Endo ${ }^{1}$
}

\begin{abstract}
A synthetic fiber rope, which is lightweight and has a high tensile strength and flexibility, is receiving much attention as a replacement for a stainless steel wire rope. This paper describes its ability to endure repetitive bending. We performed experiments in conformity with the ISO 20202 standard using ten synthetic fiber ropes made of different materials and with different compositions, along with two stainless steel wire ropes. As a result, a 7x19 stainless steel wire rope and an ultra-high molecular weight polyethylene rope (SK-71), which has a high resistance to frictional wear, did not experience significant loss of tensile strength. However, repeated bending caused the tensile strength deterioration of the other synthetic fiber ropes, which had low resistances to frictional wear. In the case of steep bending with a small pulley or bending with high tension, we experimentally revealed that some synthetic fiber ropes are superior to stainless steel wire ropes.
\end{abstract}

\section{INTRODUCTION}

Currently, synthetic fiber ropes with high performances are actively being developed. The tensile strengths of some of these are the same or larger than that of a stainless steel wire rope. Moreover, they are particularly lightweight, with a density that is $1 / 5$ to $1 / 8$ that of a stainless steel wire rope. In addition, they can be easily handled such as when making knots to fix the end in place because they are more flexible than a stainless steel wire rope. The frictional coefficients of most of these synthetic fiber ropes varied from $1 / 3$ to $1 / 5$ that of a stainless steel wire rope, implying a possibility to develop a high energy efficiency transmission mechanism. Many researchers have taken advantages of these features by applying them to tendon-driven robots [1]-[5], artificial muscles [6], and so forth.

When designing a tendon-driven mechanism with metal wire ropes, many of their characteristics (e.g., tensile strength, minimum pulley radius, and terminal fixation strength) are provided by the International Organization for Standardization (ISO) or books [7] because drive mechanisms with metal wire ropes have been widely applied in robots, elevators, cranes, and so forth for a very long time. On the other hand, in relation to synthetic fiber ropes, although manufacturers provide some of the characteristics of the original yarn [8], they only provide the tensile strength (breaking strength) as a physical property when it is constructed as a rope. Although some researchers have studied the physical properties of synthetic fiber rope [9][11], to the

\footnotetext{
*This work was supported by the JSPS Grants-in-Aid for Scientific Research (25420214) and the New Energy and Industrial Technology Development Organization (NEDO)

${ }^{1}$ Atsushi Horigome and Gen Endo are with the Department of Mechanical and Aerospace Engineering, Tokyo Institute of Technology , 2-12-1 Ookayama, Meguro-ku, Tokyo, 152-8552, Japan gendo@mes.titech.ac.jp
}

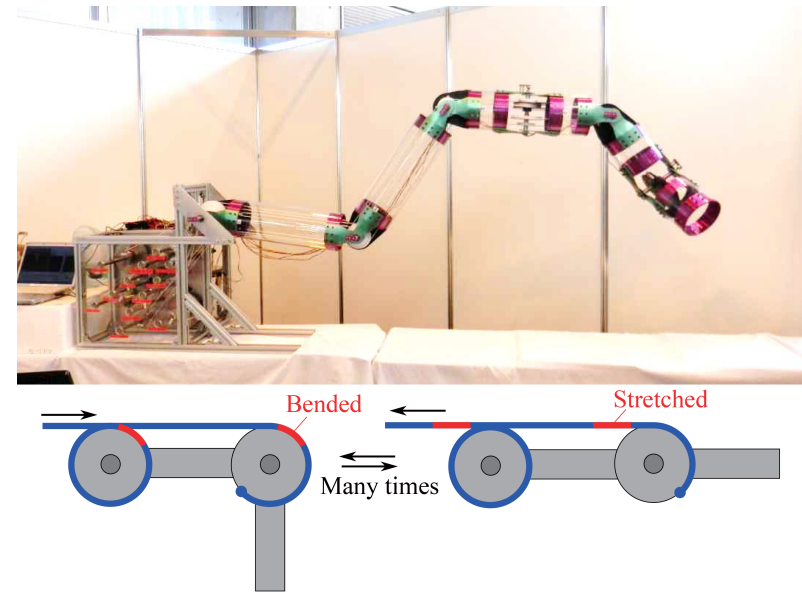

Fig. 1. Coupled tendon-driven 3D multi-joint manipulator: (top) hardware overview and (bottom) repetitive bending of tendon.

best of our knowledge, there has been no comprehensive research providing a systematic design guideline. Moreover, the physical properties supplied by individual manufacturers are difficult to compare in the rope selection process because their measurement conditions are determined by the individual manufacturers. Therefore it is very difficult to apply synthetic fiber ropes in reliable robotic applications requiring high quality assurance.

In this study, our ultimate goal is to reveal the advantages and disadvantages of various synthetic fiber ropes by comparing them to each other in standardized experiments, and provide fundamental information to establish a general design guideline for a tendon-driven robot. Advancing the study of the physical properties of the synthetic fiber ropes in the future will provide a great opportunity for developing new lightweight, compact, and robust drive mechanisms that have not been achieved with conventional metal wire ropes.

To fulfill the design guideline, we need to investigate the physical properties of the ropes such as creeping elongation, visco-elasto-plasticity, and durability against impact loading. The basic mechanical properties of a tendon-driven transmission mechanism, such as frequency response, load capacity, maximum velocity, friction, durability, terminal fixation method, are also very important.

As a first step of this study, we showed a strength reduction by static bending with a fixed pulley, where the ratio of pulley diameter $D$ and wire diameter $d$ determines the strength reduction, similar to that with a steel wire rope [12] in our previous study. In this article, we focused on the strength degradation by repetitive bending. Figure 1 shows a prototype model of a coupled tendon-driven 3D multijoint manipulator [2] designed for use in decommissioning 


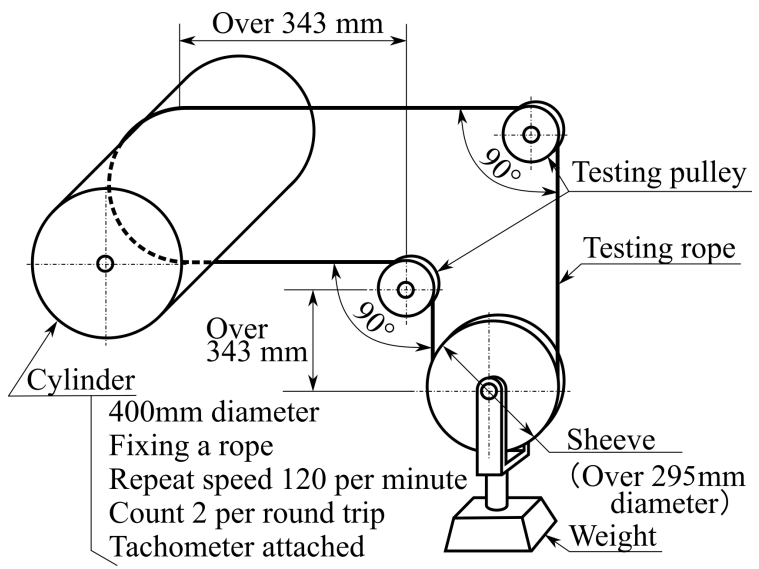

Fig. 2. Apparatus for endurance test specified in ISO 2020-2

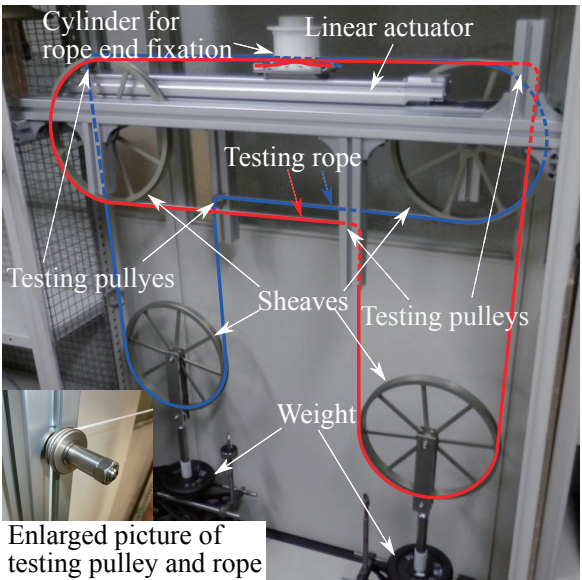
testing pulley and rope

Fig. 3. Developed experimental device using linear actuator.

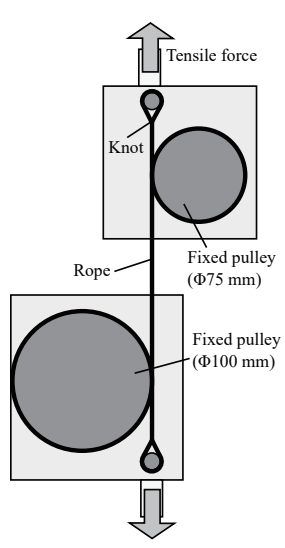

Fig. 4. Measurement of breaking strength after endurance test. tasks in the confined environments of the Fukushima Daiichi Nuclear Power Plants. Each joint is controlled by synthetic fiber tendons, which are repeatedly bent by multiple pulleys. It is essential to understand the durability of synthetic fiber ropes with repetitive bending in order to ensure the total lifetime of the manipulator.

In this regard, one reference [10] reported the results of the cyclic bend-over-sheave (CBOS) fatigue testing of $40 \mathrm{~mm}$ diameter fiber ropes. However, the experiments conditions were not suitable for a tendon-driven robot because the tests were for a thick mooring rope. Another reference [11] reported the results of repetitive bending experiments. However, there was insufficient information about the custommade apparatus, which made it difficult to double-check the results. A third reference [13] reported the results of rope endurance tests with three materials. However, because these experiments were performed using a specially designed capstan drive mechanism, it is difficult to generalize the results and apply them to various types of tendon-driven robot.

In this study, we found the strength degradation due to repetitive bending using various types of synthetic fiber ropes. In order to obtain comparable and generalized results, the test apparatus was constructed based on the ISO 20202 for the preformed flexible steel wire rope for aircraft controls. Five synthetic fiber materials with two different compositions, as well as two stainless wires ropes, were tested. We will discuss the advantages and disadvantages of these synthetic fiber ropes by comparing the results of these tests.

\section{TEST APPARATUS AND MEASUREMENT METHOD}

The International Organization of Standardization (ISO) defines an endurance test for a preformed flexible steel wire rope for aircraft controls in ISO 2020-2:1997. The tested wire rope is repeatedly bent 70,000-130,000 times by passive rotating test pulleys, and the tensile strength (breaking strength) is measured after this endurance test. The rope shall have more than $50 \%$ or $60 \%$ of the original breaking strength in the case of a carbon steel wire rope or corrosionresisting (stainless) steel wire rope, respectively. On the other hand, there is no standard regulating a repetitive bending experiment for a synthetic fiber rope. Thus, it is natural to test synthetic fiber ropes using the same apparatus as used for steel wire ropes in order to compare their durability values.

Figure 2 shows the endurance test apparatus specified in ISO 2020-2. The rope is tensioned by a weight, driven by a cylinder with a sufficiently large diameter, and bent by testing pulleys whose shape is strictly determined. This apparatus can test two samples at once. The dimension of the testing pulley and tension of the rope can be adjusted based on the diameter of the test rope. Figure 3 shows the developed experimental apparatus, which has a symmetrical structure on the front and back sides. In order to test four samples in one endurance test, we installed two ropes, as shown in the red and blue lines in Fig. 3. We used a programmable linear actuator (T6L-20-600-3L-SR1-X05N-B, YAMAHA) instead of a drive cylinder to simultaneously drive both wire ropes because this made it easy to set the distance and speed of the reciprocating motion and precisely count the number of repetitions.

The experimental conditions are listed in Table.I. The ISO 2020-2 compliant experimental conditions for a $\phi 2 \mathrm{~mm}$ rope (derived by linear interpolation from the conditions for ropes with diameters of $1.6 \mathrm{~mm}$ and $2.4 \mathrm{~mm}$ ) are marked with the * symbol. In order to investigate the advantages of synthetic fiber ropes, we performed the experiments with smaller testing pulleys, higher tension values, and a higher number of reversals because a synthetic fiber rope is expected to be used in compact mechanisms with a higher load capacity and in higher endurance applications. Typically, 70,000 repetitive motions required a testing time of approximately $9 \mathrm{~h}$ and 43

TABLE I

EXPERIMENT CONDITIONS FOR 2.0 MM ROPE DIAMETER

\begin{tabular}{|c|c|c|c|}
\hline Tension [N] & $\begin{array}{c}\text { Number of } \\
\text { repetitions } \times 10^{3}\end{array}$ & $\begin{array}{c}\text { Bent length } \\
{[\mathrm{mm}]}\end{array}$ & $\begin{array}{c}\text { Testing pulley } \\
\text { diameter }[\mathrm{mm}]\end{array}$ \\
\hline $31.3^{*}, 99.3,147$ & $10,35,70^{*}, 140$ & $350^{*}$ & $6.0,10.0,24.0^{*}$ \\
\hline
\end{tabular}


TABLE II

PHYSICAL PROPERTIES OF SYNTHETIC FIBERS[15] [16][17][18][19].

\begin{tabular}{|c|c|c|c|c|c|}
\hline Fiber name & Material & $\begin{array}{l}\text { Strength } \\
\text { [cN/dtex] }\end{array}$ & $\begin{array}{l}\text { Young's modulus } \\
\text { [cN/dtex] }\end{array}$ & $\begin{array}{c}\text { Elongation } \\
{[\%]}\end{array}$ & $\begin{array}{l}\text { Density } \\
{\left[\mathrm{g} / \mathrm{cm}^{3}\right]}\end{array}$ \\
\hline Dyneema $\AA$ SK-60 & UHPE & 28 & 900 & 4.0 & 0.97 \\
\hline Dyneema $\mathbb{R}$ SK-71 & UHPE & 37 & 1150 & 3.7 & 0.97 \\
\hline Zylon® AS & $\mathrm{PBO}$ & 37 & 1150 & 3.5 & 1.54 \\
\hline Kevlar@ 29 & Para-aramid & 19 & 440 & 4.0 & 1.44 \\
\hline Kevlar@ 49 & Para-aramid & 19 & 750 & 2.4 & 1.45 \\
\hline Technora® & Para-aramid & 25 & 520 & 4.6 & 1.39 \\
\hline Vectran@ HT & Polyarylate & 24 & 530 & 4.0 & 1.41 \\
\hline
\end{tabular}

UHPE:ultra high molecular weight polyethylene, PBO: poly(p-phenylene-2,6-benzobisoxazole).

TABLE III

ROPES TESTED IN REPETITIVE BENDING EXPERIMENTS. ALL ROPES HAD DIAMETERS OF 2MM.

\begin{tabular}{|c|c|c|c|c|c|c|c|c|c|c|c|}
\hline \multirow{2}{*}{ Name } & \multirow{2}{*}{ Model } & \multirow{2}{*}{ Supplier } & \multicolumn{3}{|c|}{ Tensile strength [kN] } & \multirow{2}{*}{$\begin{array}{l}\text { Weight } \\
{[\mathrm{g} / \mathrm{m}]}\end{array}$} & \multicolumn{2}{|c|}{ Core fiber } & \multicolumn{2}{|c|}{ Sleeve fiber } & \multirow{2}{*}{$\begin{array}{c}\operatorname{Cost}^{* 1} \\
\text { [USD } / \mathrm{m} \text { ] }\end{array}$} \\
\hline & & & Measured & Estimated & $\%$ & & Fiber & Structure & Fiber & Structure & \\
\hline Dyneemal & DB-60 & $\begin{array}{l}\text { Hayami } \\
\text { industry }\end{array}$ & 2.14 & 3.94 & 54 & 1.7 & $\begin{array}{c}\text { Dyneema }{ }^{\circledR} \\
\text { SK-60 } \\
\text { UHPE }\end{array}$ & $\begin{array}{c}1760 \text { dtex } \\
\times 8 \text { strand } \\
\text { braid }\end{array}$ & & & 0.81 \\
\hline Dyneema2 & DB-96HSL & $\begin{array}{l}\text { Hayami } \\
\text { industry }\end{array}$ & 4.29 & 7.81 & 54 & 2.4 & $\begin{array}{c}\text { Dyneema }{ }^{\circledR} \\
\text { SK-71 } \\
\text { UHPE }\end{array}$ & $\begin{array}{c}2640 \text { dtex } \\
\times 8 \text { strand } \\
\text { braid }\end{array}$ & & & 1.62 \\
\hline Zylon1 & SZ-20 & $\begin{array}{l}\text { Hayami } \\
\text { industry }\end{array}$ & 2.86 & 3.71 & 77 & 3.2 & $\begin{array}{c}\text { Zylon }{ }^{\circledR} \\
\text { AS } \\
\text { PBO }\end{array}$ & 10020 dtex & Polyester & $\begin{array}{c}1100 \mathrm{dtex} \\
\times 16 \text { strand } \\
\text { braid }\end{array}$ & 1.08 \\
\hline Zylon2 & ZB-308 & $\begin{array}{l}\text { Hayami } \\
\text { industry }\end{array}$ & 6.59 & 9.89 & 66 & 2.9 & $\begin{array}{c}\text { Zylon }{ }^{\circledR} \\
\text { AS } \\
\text { PBO }\end{array}$ & $\begin{array}{c}3340 \text { dtex } \\
\times 8 \text { strand } \\
\text { braid }\end{array}$ & & & 1.8 \\
\hline Kevlarl & S-20 & $\begin{array}{l}\text { Hayami } \\
\text { industry }\end{array}$ & 2.37 & 2.55 & 92 & 3.6 & $\begin{array}{c}\text { Kevlar } \\
49 \\
\text { Para-aramid }\end{array}$ & 13400 dtex & Polyester & $\begin{array}{c}1110 \text { dtex } \\
\times 16 \text { strand } \\
\text { braid }\end{array}$ & 0.72 \\
\hline Kevlar2 & KB-308 & $\begin{array}{l}\text { Hayami } \\
\text { industry }\end{array}$ & 4.08 & 5.08 & 80 & 3.0 & $\begin{array}{c}\text { Kevlar }{ }^{\circledR} \\
29 \\
\text { Para-aramid }\end{array}$ & $\begin{array}{c}3340 \text { dtex } \\
\times 8 \text { strand } \\
\text { braid }\end{array}$ & & & 1.17 \\
\hline Technoral & STB-20 & $\begin{array}{l}\text { Hayami } \\
\text { industry }\end{array}$ & 3.01 & 3.34 & 90 & 3.0 & $\begin{array}{c}\text { Technora }{ }^{\circledR} \\
\text { Para-aramid }\end{array}$ & $\begin{array}{c}1670 \text { dtex } \\
\times 8 \text { strand } \\
\text { braid }\end{array}$ & Polyester & $\begin{array}{c}440 \mathrm{dtex} \\
\times 24 \text { strand } \\
\text { braid }\end{array}$ & $0.81^{* 2}$ \\
\hline Technor & TNB-308 & $\begin{array}{l}\text { Hayami } \\
\text { industry }\end{array}$ & 4.37 & 6.68 & 65 & 2.9 & $\begin{array}{c}\text { Technora }(\mathbb{R}) \\
\text { Para-aramid }\end{array}$ & $\begin{array}{c}3340 \text { dtex } \\
\times 8 \text { strand } \\
\text { braid }\end{array}$ & & & $0.99^{* 2}$ \\
\hline & SV-20 & $\begin{array}{l}\text { Hayami } \\
\text { industry }\end{array}$ & 2.53 & 3.21 & 78 & 3.2 & $\begin{array}{c}\text { Vectran }{ }^{\circledR} \\
\text { HT } \\
\text { Polyarylate }\end{array}$ & $\begin{array}{c}1670 \text { dtex } \\
\times 8 \text { strand } \\
\text { braid }\end{array}$ & Polyester & $\begin{array}{c}1100 \mathrm{dtex} \\
\times 16 \text { strand } \\
\text { braid }\end{array}$ & 0.99 \\
\hline Vectran2 & VB-308 & $\begin{array}{l}\text { Hayami } \\
\text { industry }\end{array}$ & 4.18 & 6.41 & 65 & 2.9 & $\begin{array}{c}\text { Vectran }{ }^{\circledR} \\
\text { HT } \\
\text { Polyarylate }\end{array}$ & $\begin{array}{c}3340 \text { dtex } \\
\times 8 \text { strand } \\
\text { braid }\end{array}$ & & & 1.08 \\
\hline Stainless 1 & SC-200 & SHINYO & 3.56 & - & & 16 & SUS304 & $7 \times 19$ & & & $1.61^{* 3}$ \\
\hline Stainless2 & SB-200 & SHINYO & 3.55 & - & & 16 & SUS304 & $7 \times 7$ & & & $1.03^{* 3}$ \\
\hline
\end{tabular}

$\min$.

After a specified number of reciprocating motions, the breaking strength was measured to evaluate the degradation of the tensile strength. A schematic representation of the tensile strength is shown in Fig. 4. Because a synthetic fiber rope has a small frictional coefficient, we carefully selected the end-point fixation method. In order to tightly fix the end of the test rope, a loop was formed by a knot and it hung on a pin with a $6 \mathrm{~mm}$ diameter. The upper and lower extremities of the test rope were wound around fixed pulleys for three or more turns to exploit belt friction. Ideally, the pulley radii should be as large as possible to eliminate strength degradation due to static bending. However, we chose pulleys with diameters of $\phi 75 \mathrm{~mm}$ and $\phi 100 \mathrm{~mm}$ to reduce the total length of the testing ropes. In our previous work [12], the diameters of both fixed pulleys were sufficiently large to prevent a decrease in the breaking strengths of a $\phi 2.0 \mathrm{~mm}$ rope. We measured the tensile strengths of the ropes using tensile testing device (AG-I, Shimadzu co., $100 \mathrm{kN}$ maximum load) until the test ropes broke, where the stretching velocity was $300 \mathrm{~mm} / \mathrm{min}$

\section{ROPES TESTED}

Table II lists the physical properties of the yarn used to construct the test ropes. Table III lists the specifications of the constructed test ropes. All of the ropes had a diameter of $2 \mathrm{~mm}$. Basically, there were two types of construction. One was a single layer rope with an eight strand braid 
to achieve the highest tensile strength. ${ }^{1}$ The other was a two-layer types where the core fibers were covered with sleeve fibers to prevent the rope surface from wearing. In this construction, although the core fibers were protected, the maximum tensile strength decreased because the tensile force was always supported only by the core fibers, with no contribution from the sleeve fibers in supporting the tensile force because of the deformable mesh braiding. Because the outer diameter of the rope was equals to $\phi 2 \mathrm{~mm}$, two-layer ropes had fewer core fibers.

It should be noted that most of the measured tensile strengths obtained in the experiment without the endurance test shown in Fig. 4 were only $50-70 \%$ of the estimated values calculated by multiplying the yarn strength by the number of yarn fibers. This might be because of the differences in the lengths of the eight strands and the mutual strands damage during the tensile strength test.

In order to compare these synthetic fiber ropes with stainless steel ropes, we prepared ropes with two different configuration: $7 \times 19$ and $7 \times 7$. We performed endurance tests for a total of twelve types of ropes, as discussed in the following section.

\section{EXPERIMENTS}

We performed the experiment as follows.

1) The weight was adjusted to add the specified tension.

2) The weight was supported by a jack, and the test rope was set into place.

3) The jack was lowered to apply tension to the test rope.

4) Reciprocal movements were applied for a specified number of bending repetitions.

5) The rope was removed, and four samples were obtained.

6) The breaking tensile strength was measured for three of the samples.

We carefully fixed the extremities of the test rope to the tensile measurement jigs in order to place the tested part between the upper and lower jigs to correctly measure the breaking strength of the bent section. The measured tensile strength was obtained by averaging the values for three samples. In the following figures, each of the error bars shows the standard error of three samples. Here, we define the strength efficiency in the following equation.

Strength efficiency $=$

$$
\frac{\text { Tensile strength after repetitive bending }}{\text { Tensile strength before repetitive bending }} \%
$$

Both the breaking strength and strength efficiency are discussed in the following section.

\section{A. ISO 2020-2 compliance test}

We performed the endurance experiments based on the ISO 2020-2 specified conditions listed in Table I. The breaking strength measurement results are shown in Fig.5.

\footnotetext{
${ }^{1}$ Dyneemal was a standard product from the rope manufacturer, whereas the others were custom-made ropes designed to obtain the maximum fiber density.
}

The white bars in Fig.5 indicate the original breaking strength without repetitive bending. The tensile strengths of all of the synthetic fiber ropes except Dyneemal and Dyneema2 were substantially decreased by repetitive bending. In particular, even though Zylon2 had the maximum original tensile strength among all the tested ropes, its tensile strength significantly decreased, becoming smaller than those of Dyneema2 and Stainless1 after the repetitive bending test, which suggested that PBO fiber ropes are greatly affected by repetitive bending. These results also showed that evaluating the repetitive bending endurance is extremely important for a practical driving mechanism.

These experiments confirmed that two layer construction was not effective at increasing the fatigue life time of the rope. The strength degradation seemed to be mainly caused by the mutual friction between the strands of the core fibers, because the breaking strengths of the two-layered ropes ( $\mathrm{Zy}$ lon1, Kevlar1, Technora1 and Vectran1) were significantly decreased.

Figure 6 shows the strength efficiencies of the tested ropes. In the case of the Stainless1 rope, the strength efficiency is nearly equal to $100 \%$. Dyneema1 and Dyneema2 also have

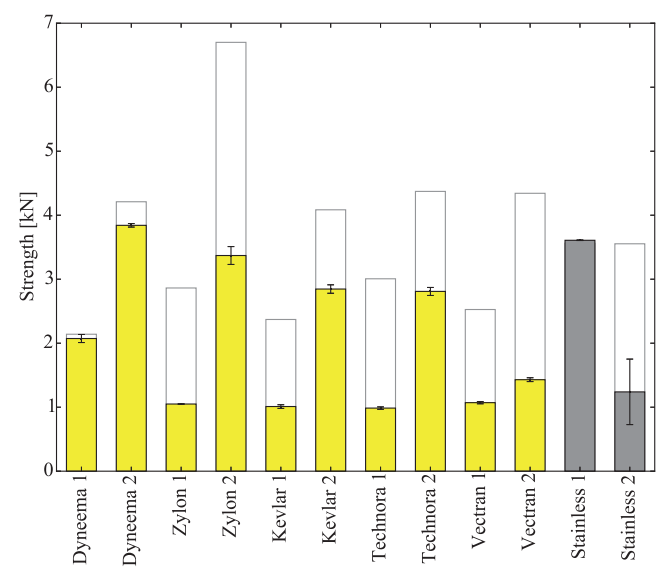

Fig. 5. Tensile strength after repetitive bending experiment based on ISO 2020-2. The white bars show the original tensile strengths without repetitive bending.

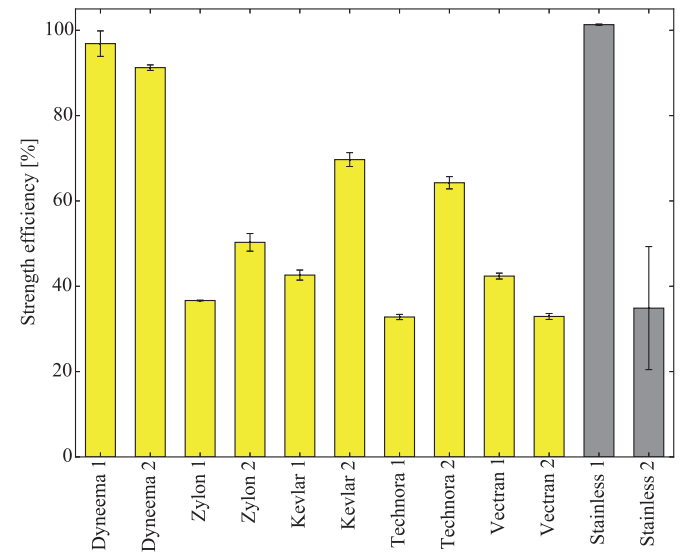

Fig. 6. Strength efficiency after repetitive bending experiment based on ISO 2020-20. 


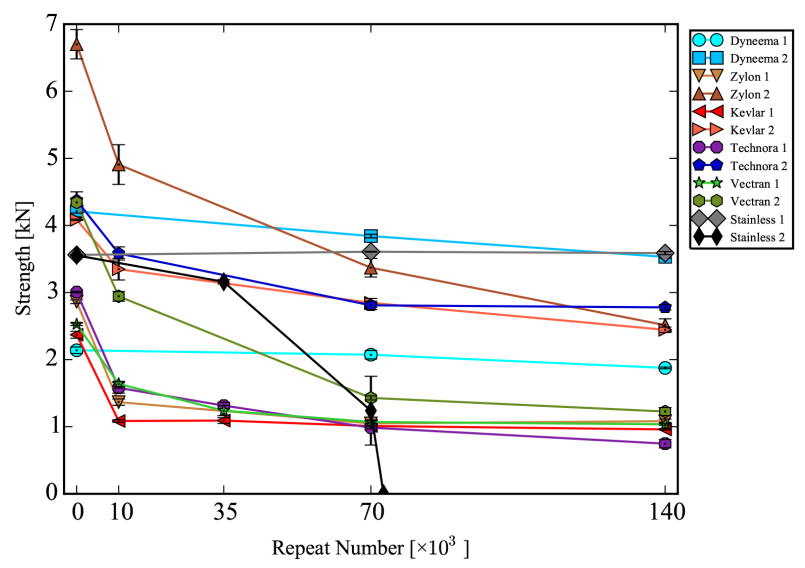

Fig. 7. Relationship between number of repetitions and tensile strength. (Tension: $31.3 \mathrm{~N}$, testing pulley diameter: $24.0 \mathrm{~mm}$ )

competitive high strength efficiencies more than $90 \%$. These results imply that these ropes are suitable for repetitive bending operations over long periods. In contrast, the strength efficiency of Stainless2 became approximately 35\%. This was because of the larger stress due to the thick stainless steel wire of $\phi 0.22 \mathrm{~mm}$, which was 1.7 times higher than that of Stainless1.

\section{B. Relationship between number of bending repetitions and strength}

In order to investigate the relationship between the number of bending repetitions and the tensile strength, the number of bending repetitions was set to $10,35,140 \times 10^{3}$, whereas the other experimental conditions were kept the same. (We omitted the tensile strength measurement with the smaller number of bending repetitions if there was no significant degradation after $70 \times 10^{3}$ bending repetitions as shown in the previous subsection.)

Figures 7 and 8 show the experimental results for the tensile strength and strength efficiency, respectively. A repetition value of zero indicates the original strength before the bending test.

With the exception of Dyneema1 and Dyneema2, the synthetic fiber ropes showed rapid strength decreases during the initial $10 \times 10^{3}$ bending repetitions. After $70 \times 10^{3}$ bending repetitions, their strength degradations became gradual. In contrast, Stainless1, Dyneema1, and Dyneema2 retained an almost constant strength or showed only a slight degradation. Stainless 2 broke at $73 \times 10^{3}$ bending repetitions as a result of the high bending stress of its thick strands.

In summary, the tensile strength of a synthetic fiber rope decreased in accordance with the number of bending repetitions, and the degree of decrease became more gradual as the number of bending repetitions increased. Although a stainless wire rope with thick strands was broken, we did not observe any strength degradation of a stainless wire rope with thin strands, which suggested that a stainless wire rope with thin strands was superior to the synthetic fiber ropes under this experiment condition.

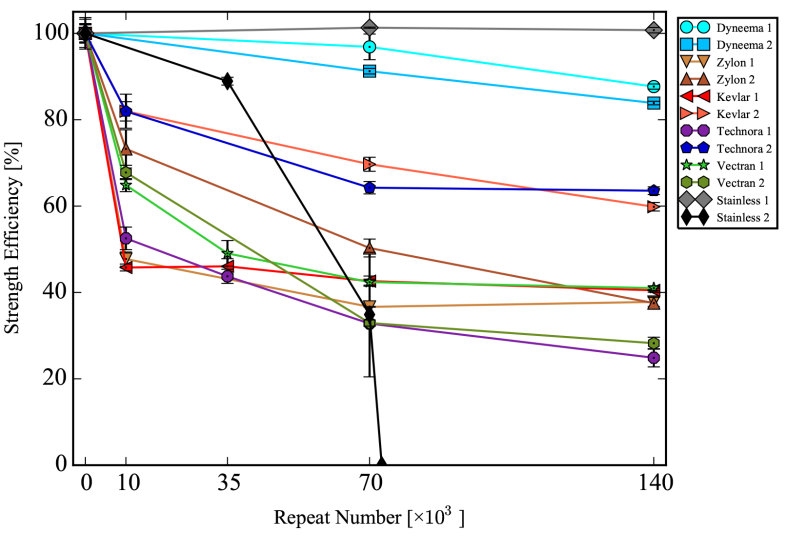

Fig. 8. Relationship between number of repetitions and strength efficiency. (Tension: $31.3 \mathrm{~N}$, testing pulley diameter: $24.0 \mathrm{~mm}$ )

\section{Relationship between tension and strength}

The tension specified in ISO $2020-2$ is $31.3 \mathrm{~N}$, which is less than $1 \%$ of the breaking strength. Thus, this condition is not plausible for the driving mechanism of a robot joint. Ideally, repetitive bending tests should be performed under various magnitudes of tension. As a first step of this investigation, the rope tensions were changed from $31.3 \mathrm{~N}$ to $147.0 \mathrm{~N}$ based on a consideration of the mechanical strength of the experimental apparatus, and the relationship between the tension and strength was investigated. Figures 9 and 10 show the breaking strength and strength efficiency, respectively, where the horizontal axes indicates the tension values of the ropes. The original strength and its efficiency before the repetitive bending test are plotted at a tension of zero. If the ropes broke during the repetitive bending test, the data are plotted on the horizontal axis.

It was verified that the strengths of all the ropes except Vectran 1 decreased as the tension increased. As for the Zylon, Kevlar, and Vectran, the two-layer structure was effective at maintaining the strength under repetitive bending. As for the stainless ropes, Stainless 2 broke when 99.3 N was applied, and the strength of Stainless1 greatly decreased when 147.0 N was applied. When 147.0 N applied, Dyneema1, Dyneema2, and Technora2 were superior to Stainless1, which suggested that these synthetic fiber ropes had higher repetitive bending endurance values than the stainless steel ropes under a higher tension.

\section{Relationship between testing pulley radius and strength}

Because a synthetic fiber rope is very flexible and does not require a high bending moment compared with a metal wire rope, synthetic fiber ropes are frequently used for compact drive mechanisms [3][4]. In our previous work [12], static bending was shown to cause as strength reduction similar to that in metal wire ropes. For example, in a case where ratio $D / d$ equals 1 (pulley radius $D$ equals rope radius $d$ ), the strength efficiency becomes approximately 40-50\%. In this experiment, we measured the repetitive bending endurance with smaller pulleys. We changed the testing pulley radius 


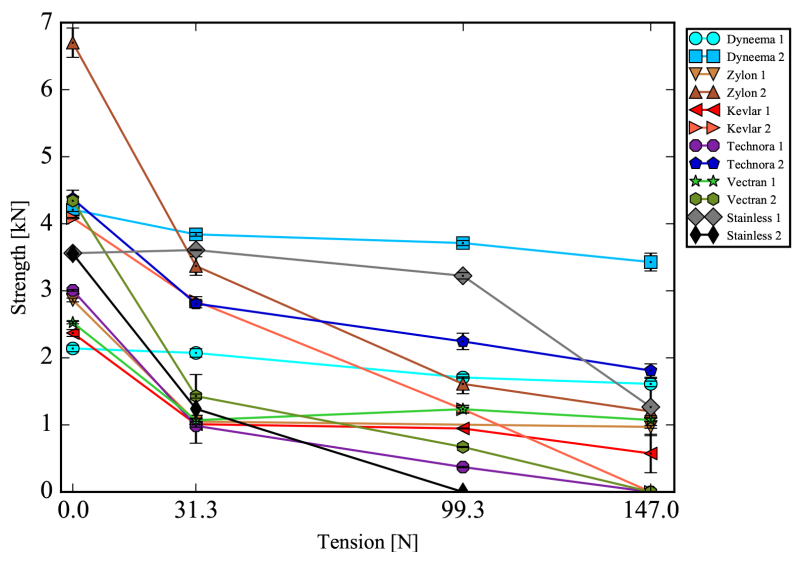

Fig. 9. Relationship between tension and tensile strength. (Number of repetitions: $70 \times 10^{3}$, testing pulley diameter: $24.0 \mathrm{~mm}$ )

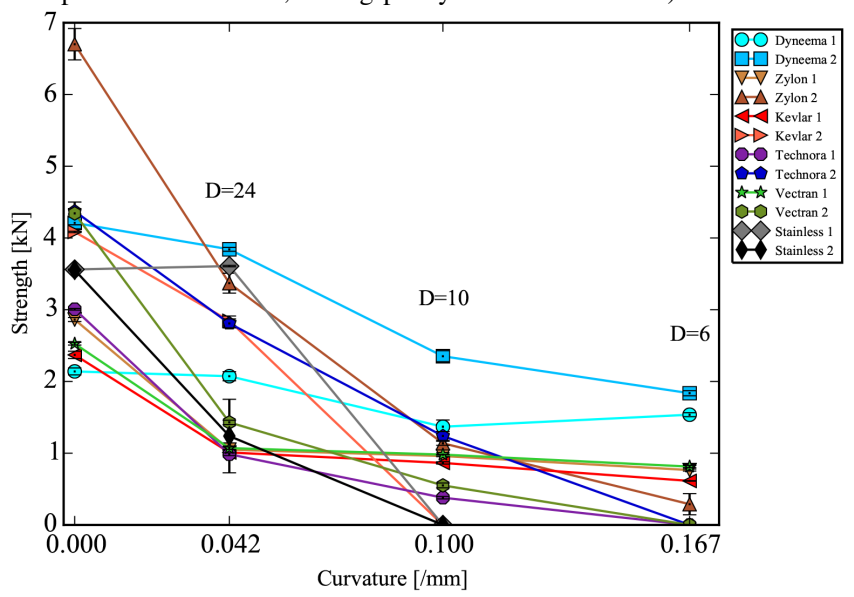

Fig. 11. Relation between test pulley diameter and tensile strength (Tension: $31.3 \mathrm{~N}$, number of repetitions: $70 \times 10^{3}$ )

to apply much sharper bending, assuming a compact mechanism. Pulley diameters of $\phi 24 \mathrm{~mm}, 10 \mathrm{~mm}$, and $6 \mathrm{~mm}$ were used for the bending tests. The other experimental parameters were kept the same as the ISO 2020-2 compliant conditions.

Figures 11 and 12 show the breaking strength and strength efficiency, respectively. The horizontal axes indicate the curvature of the testing pulley (1/radius), and the plots on the horizontal origin were obtained from original measured rope strength without repetitive bending tests. Stainless1, Stainless2, and Kevlar2 broke during the bending experiments with the $10 \mathrm{~mm}$ testing pulley. In contrast, all of the synthetic fiber ropes except for Kevlar2 survived under the same condition. Moreover, in the case of the $6 \mathrm{~mm}$ testing pulley, none of the six synthetic fiber ropes broke. In particular, Dyneema1 and Dyneema2 retained more than $40 \%$ of their original strengths, suggesting that Dyneema is suitable for a compact mechanism.

In summary, the synthetic fiber ropes were generally found to be superior to stainless wire ropes in the case of repetitive bending with small pulleys. In particular, the Dyneemal and Dyneema2 ropes could withstand sharp bending.

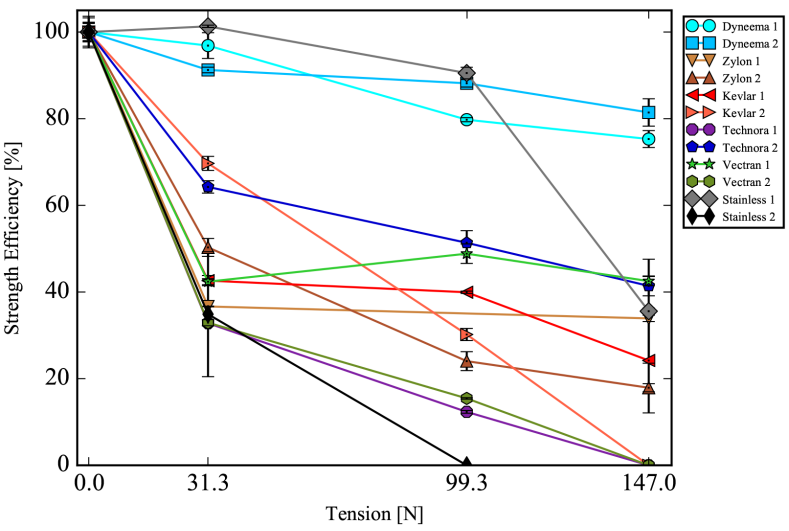

Fig. 10. Relationship between tension and strength efficiency. (Number of repetitions: $70 \times 10^{3}$, testing pulley diameter: $24.0 \mathrm{~mm}$ )

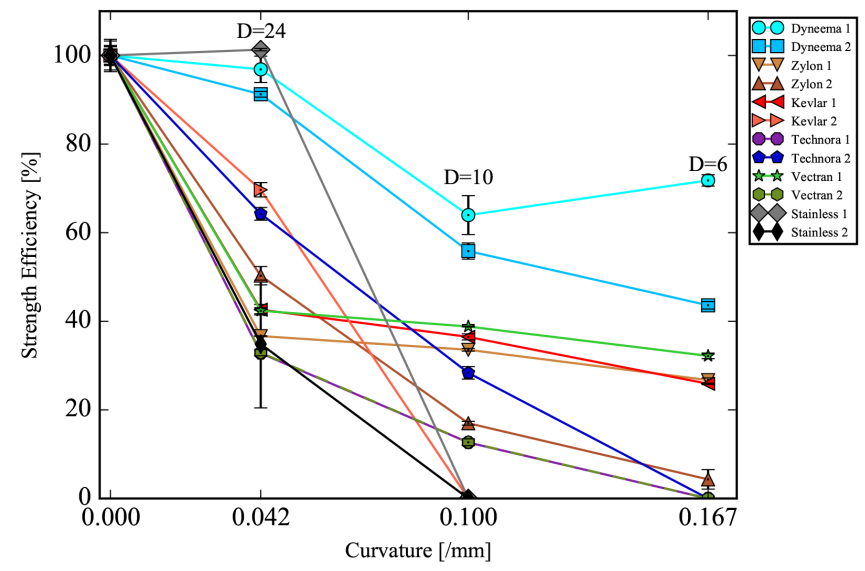

Fig. 12. Relation between test pulley diameter and strength efficiency. (Tension: $31.3 \mathrm{~N}$, number of repetitions: $70 \times 10^{3}$ ) Note that the Technora1 data are incidentally almost the same value of Vectran 2 .

\section{Discussion}

Because a synthetic fiber rope is more flexible than a metal wire rope, it is expected to possess higher durability against repetitive bending. However, based on the results of ISO 2020-2 compliant experiments, the tensile strengths of almost all the synthetic fiber ropes substantially decreased whereas a stainless wire rope with thin strands did not show tensile strength decrease. Only four ropes, Dyneema1, Dyneema2, Kevlar2, and Technora2, satisfied the requirement of the ISO standards that shall have $50-60 \%$ of the original strength after $7.0 \times 10^{4}$ bending repetitions. Among the four synthetic fiber ropes, Dyneema2 had a slightly higher residual strength than Stainless1. This result was different from our initial expectations.

Using a synthetic fiber rope definitely reduces the total weight of a tendon-driven robot. However, is this the only apparent advantage to choose a synthetic fiber rope? In order to answer this question, we changed the experimental conditions by increasing the rope tensions as well as the number of bending repetitions. In this case, Stainless2, which had thick strands, broke during the experiment, while the synthetic fiber ropes did not. Moreover, Dyneema1, Dyneema2, and Technora2 were superior to Stainless1, which had thin strands, in terms of both the tensile strength and strength 
efficiency under the higher tension. Finally, a sharper bending endurance test showed that the synthetic fiber ropes definitely had high durability values than the stainless wire ropes. These results quantitatively supported the conclusion that a synthetic fiber rope can be used to make a compact tendon-driven mechanism with a high load capacity and high endurance.

In our previous work[5], we developed a lightweight sprawling-type quadruped robot using tendon-driven joints with synthetic fiber ropes (Fig.13). The hip joints used a new compact speed reduction mechanism, where $\phi 1.05 \mathrm{~mm}$ Dyneema2 rope was wound around a thin input shaft of $\phi 5.5 \mathrm{~mm}$. In this case, $D / d$ becomes 5.23 . We selected the synthetic fiber rope because of the difficulty of assembling the robot with stainless wire rope, and to reduce the weight of the robot, and maximize leg's output force. However, at that time, we could not quantitatively justify our selection in terms of durability.

The results reported in this paper clearly show that if stainless wire ropes were used for that quadruped robot, it could not walk 70,000 steps because of the rope's low endurance against sharp bending. In contrast, it is estimated that using Dyneema2 ropes will make it possible to achieve at least 140,000 steps. If the quadruped robot walks with a maximum speed of $1.38 \mathrm{~m} / \mathrm{s}$, with a duty factor of 0.55 , stride of approximately $0.2 \mathrm{~m}$, and walking period of 0.318 $\mathrm{s}$, it is estimated that the robot could walk $61.5 \mathrm{~km}$ over 12 $\mathrm{h}$ and $20 \mathrm{~min}$. After 140,000 steps, two diagonal legs could still support $232 \mathrm{~N}$, which is more than four times the total weight of the body.

As previously mentioned, the results described in this paper contribute to the design and quantitative evaluation of a new tendon-driven robot mechanism.

\section{CONCLUSION}

In this paper, we focused on the strength reduction produced by the repetitive bending of a synthetic fiber rope and measured the durability using the ISO provided experiment. The contributions of this paper are summarized as follows.

- The tensile strength of a synthetic fiber ropes is decreased by repetitive bending.

- Although the PBO fiber ropes had the highest original strengths, they were highly degraded by repetitive bending.

- UHPE ropes could withstand repetitive bending.

- Some synthetic fiber ropes were superior to stainless wire ropes under higher load and smaller pulley bending conditions.

This paper provided basic information about using synthetic fiber ropes for a tendon-driven robot, which will assist researchers and developers in choosing appropriate ropes. We plan to continue updating the data by adding new materials such as SK-75 and SK-99 in the near future. Repetitive bending test under a considerably high tension, such as $50 \%$ of the breaking strength, is also required for practical robotic applications.
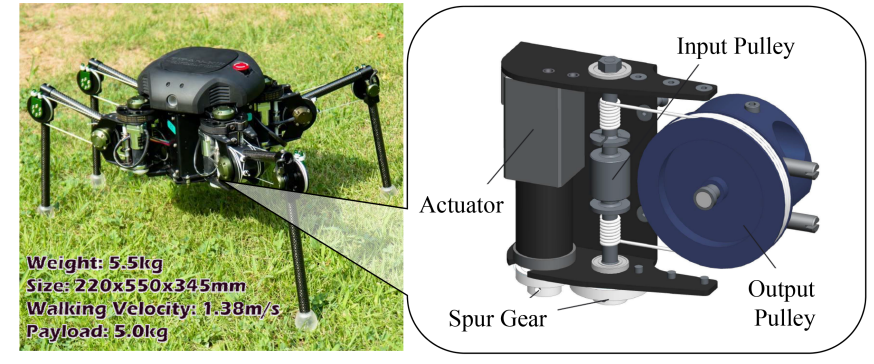

Fig. 13. Sprawling-type quadruped robot TITAN-XIII and its tendon-driven joint mechanism.

In this paper, we particularly focused on the strength degradation caused by repetitive bending. However, in order to establish a comprehensive design guideline for using synthetic fiber ropes for a tendon-driven robot, we need to investigate various properties such as the strength against impact, creeping elongation, visco-elasto-plastic deformation, the effect of lubrication, aging degradation, weather resistance, heat resistance, and so on. Moreover, the development of basic mechanical elements such as an end fixation method, and driving pulley with groove will be important topics in future work to achieve a high performance tendon-driven robot with synthetic fiber rope.

\section{ACKNOWLEDGEMENT}

The authors would like to thank Mrs. Miwa Ishikawa and Mr. Youki Wakabayashi for the execution of the time-consuming repetitive bending experiments. The authors would also like to thank the Todoroki and Mizutani Laboratory in the School of Engineering of the Tokyo Institute of Technology, which owns the tensile testing device we used. This paper was based on results obtained from a project commissioned by the New Energy and Industrial Technology Development Organization (NEDO). This work was also partially supported by a Grant-in-Aid for Scientific Research(C) 25420214.

\section{REFERENCES}

[1] Y. Nakanishi, Y. Asano, T. Kozuki, H. Mizoguchi, Y. Motegi, M. Osada, T. Shirai, J. Urata, K. Okada, and M. Inaba, "Design concept of detail musculoskeletal humanoid "Kenshiro" - Toward a real human body musculoskeletal simulator." in Proc. IEEE Int. Conf. Human. Robot., Osaka, Japan, 2012, pp. 1-6.

[2] A. Horigome, H. Yamada, G. Endo, S. Sen, S. Hirose, and E.F. Fukushima, "Development of a Coupled Tendon-Driven 3D Multijoint Manipulator.", in Proc. IEEE Int. Conf. Robot. Autom., Hong Kong, China, 2014, pp.5915-5920.

[3] T. Treratanakulwong, H. Kaminaga and Y. Nakamura, "Low-Friction Tendon-Driven Robot Hand with Carpal Tunnel Mechanism in the Palm by Optimal 3D Allocation of Pulleys.", in Proc. IEEE Int. Conf. Robot. Autom., Hong Kong, China, 2014, pp.6739-6744.

[4] W. Friedl, M. Chalon, J. Reinecke and M. Grebenstein, "FRCEF: The New Friction Reduced and Coupling Enhanced Finger for the Awiwi hand", in Proc. IEEE Int. Conf. Human. Robot., Seoul, Korea, 2015, pp.140-147.

[5] S. Kitano, S. Hirose, A. Horigome and G. Endo, "TITAN-XIII: sprawling-type quadruped robot with ability of fast and evergyefficient walking.", ROBOM. Journ., Vol. 3, No.8, 2016, DOI: 10.1186/s40648-016-0047-1. 
[6] M. Mori, K. Suzumori, S. Seita, M. Takahashi, T. Hosoda, and K. Kusumoto, "Development of Very High Force Hydraulic McKibben Artificial Muscle and Its Application to Shape-Adaptable Power Hand.", in Proc. IEEE Int. Conf. Robot. Biom., 2009, pp. 1457-1462.

[7] Charles Mischke and Joseph Shigley, "Mechanical Engineering Design.", McGraw-Hill, United States of America, 1989, fifth edition.

[8] TOYOBO Dyneema properties, 2015. [Online]. Available: http: //www.toyobo-global.com/seihin/dn/dyneema/ seihin/tokutyou.htm, Accessed on : Aug. 1, 2015.

[9] J. Kirchhoff and O. V. Stryk, "New Insights in Synthetic Fiber Rope Elongation and its Detection for Ultra Lightweight Tendon Driven Series Elastic Robots.", in Proc. IEEE Int. Conf. Adv. Intel. Mech., Munich, Germany, 2017, pp. 64-69.

[10] F. Sloan, S. Bull and R. Longerich, "Design Modifications to Increase Fatigue Life of Fiber Ropes.", in Proc. MTS/IEEE OCEANS, Washington, DC, USA, 2005, DOI: 10.1109/OCEANS.2005.1639856.

[11] Michael P. Summers, "Rope selection for rope drive transmissions used in robotic manipulation.", Oreg. State Univ, 2010, Bach. Thes.

[12] A. Horigome and G. Endo, "Basic study for drive mechanism with synthetic fiber rope -investigation of strength reduction by bending and terminal fixation method.", Advan. Robot., Vol.30, Issue 3, 2016, pp.206-217.

[13] A. Mazumdar, S. J. Spencer, C. Hobart, J. Dabling, T. Blada, K. Dullea, M. Kuehl, and S. P. Buerger, "Synthetic Fiber Capstan Drives For Highly Efficient, Torque Controlled, Robotic Applications.", IEEE Robot. Autom. Lett., Vol. 2, Issue 2, 2017, pp.554-561.

[14] ISO2020-2:1997, 2017. [Online]. Available: https://www.iso. org/standard/6788.html, Accessed on : Nov. 23, 2017.

[15] J. L. J. VAN. Dingenen, "Gel-spun high-performance polyethylene fibres.”, in J. W. S. Hearle (Eds.), High-performance fibres, Woodhead Publishing Limited, 2001, pp.69.

[16] R. B. Durairaj, "Resorcinol: Chemistry, Technology and Applications.", Springer, 2005, pp.402.

[17] J. L. Cooper and H. Sakai, "Aramid Fiber Kevlarßand its Applications.", Sen'i Gakkaishi, Vol. 43, No.4, 1987, pp.125-129. (in Japanese)

[18] S. Hiratsuka and M. Tatsui, "Development of High Strength and High Modulus Para-Aramid Fiber.", Nippon Kagaku Kaishi, Vol.1992, No.3, 1992, pp.237-245. (in Japanese)

[19] Y. Yan, "Developments in fibers for technical nonwovens.", in G. Kellie (Eds.), Advances in Technical Nonwovens, Woodhead Publishing, 2016, pp.82. 